\title{
Spontaneous rupture of a congenital diaphragmatic eventration in an infant
}

\author{
Soumitra Saha, Harshjeet Singh Bal, Sudipta Sen
}

Correspondence to Dr Harshjeet Singh Bal, balharsh@gmail.com

Accepted 17 April 2015

CrossMark

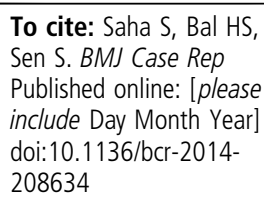

\section{Department of Paediatric Surgery, Christian Medical \\ College, Vellore, Tamilnadu, India}

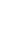

(1)

\section{TREATMENT}

The child was intubated in the emergency department and shifted to paediatric intensive care unit. He was kept on ventilatory support for a day. Surgery was planned on the probable diagnosis of a diaphragmatic hernia based on clinical and radiological findings.

At laparotomy, the small bowel, large bowel and the left lobe of liver, were seen in the left chest cavity, passing through a defect in the diaphragmatic sac (figure 2A, B). The central part of the eventrated diaphragm was seen to be thin and translucent with a $4 \times 3 \mathrm{~cm}$ defect, having ragged margins (figure $2 \mathrm{C}$ ). The entire sac with the central perforation was excised. The anterior and posterior lips of the remnant healthy diaphragm were duly approximated by placing horizontal mattress sutures using 3-0 polypropylene (figure 2D). An $8 \mathrm{Fr}$ infant feeding tube was placed in the left chest for drainage.

Postsurgery, the child was mechanically ventilated for 2 days. A chest X-ray taken on the second postoperative day showed resolution of the mediastinal shift with a normal diaphragmatic contour (figure 3). An ABG analysis concurrently revealed: $\mathrm{pH} 7.42$, $\mathrm{PaCO}_{2} 38 \mathrm{~mm} \mathrm{Hg}, \mathrm{PaO}_{2} 228 \mathrm{~mm} \mathrm{Hg}$, base-excess $0.2 \mathrm{mmol} / \mathrm{L}$ and $\mathrm{sO}_{2} 99.8 \%$.

A 5-month-old male infant presented to the paediatric emergency department with sudden onset of breathlessness. There was no history of noisy breathing, cough, fever, abdominal distension or vomiting. There was no history of trauma or preceding respiratory symptoms. On examination, the child was drowsy, cyanosed and lethargic. He had cold and clammy peripheries. His pulse rate was $160 / \mathrm{min}$ and respiratory rate was 66 breaths/min. Respiratory examination showed absent breath sounds on the left side with a right-sided tracheal shift. Abdominal examination was unremarkable.

\section{INVESTIGATIONS}

A chest X-ray showed multiple gas-filled bowel loops occupying the left side of the chest with a resultant mediastinal shift to the right (figure 1). At admission, an arterial blood gas (ABG) analysis showed the following: $\mathrm{pH} 7.39, \mathrm{PaCO}_{2} 33 \mathrm{~mm} \mathrm{Hg}$, $\mathrm{PaO}_{2} 48 \mathrm{~mm} \mathrm{Hg}$, base excess $-4.5 \mathrm{mmol} / \mathrm{L}$ and $\mathrm{SO}_{2} 83.6 \%$.

\section{DIFFERENTIAL DIAGNOSIS}

- Diaphragmatic hernia

- Traumatic diaphragmatic rupture

- Congenital diaphragmatic eventration

- Acute pneumonia
Oral feeds were started on the third postoperative day and the child was discharged on the eighth postoperative day. At 7-month follow-up, the child is asymptomatic and well.

\section{DISCUSSION}

Spontaneous diaphragmatic rupture in children is rare, with only five reported cases in the English literature. $^{1}{ }^{3-6}$ Of the five, three had associated respiratory illness and one had physical exertion as the cause for diaphragmatic rupture.

Diaphragmatic rupture seen in association with eventration of the diaphragm is extremely rare with only two reported cases in the English literature. Of the two, Lone $e t a l^{2}$ described a 4-year-old boy who had a traumatic rupture of the eventrated diaphragm, while Gun et $a l^{1}$ described a 15 -monthold male infant, a known asthmatic, who had a rupture of the eventrated diaphragm. In the latter case, the rupture may have been due to chronic cough-obstructive airway disease rather than spontaneous. Thus, ours is the only case where an antecedent cause for diaphragmatic rupture was not found.

\section{OUTCOME AND FOLLOW-UP}




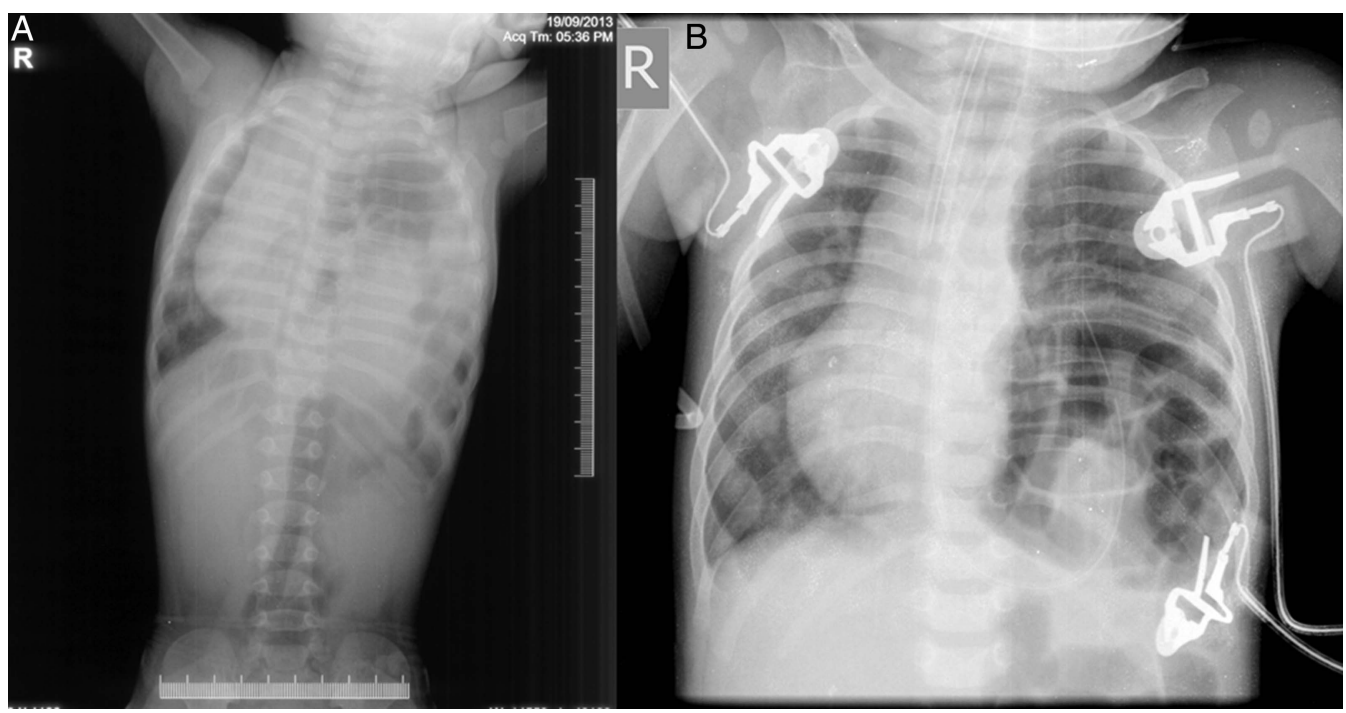

Figure 1 Chest X-ray (A) at presentation and (B) after ventilation.

Common symptoms of spontaneous diaphragmatic rupture are pain, nausea, vomiting and dyspnoea. Left-sided ruptures are more common than those on the right. The differentials considered in our case were congenital diaphragmatic hernia, traumatic diaphragmatic rupture, congenital diaphragmatic eventration and acute pneumonia. While it is difficult to clinically differentiate the first three conditions, absence of systemic signs helps in ruling out infectious pneumonia as a cause for

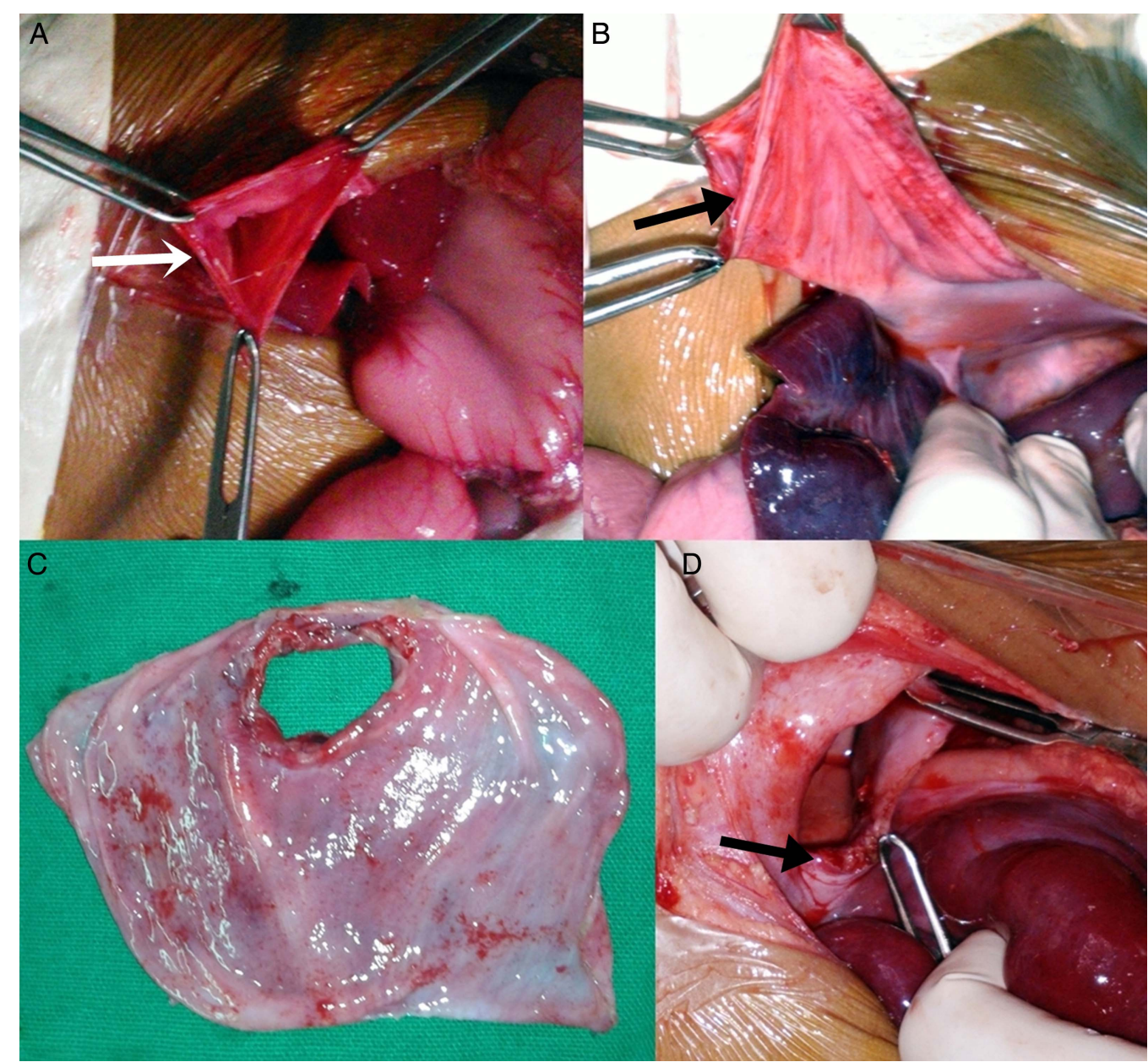

Figure 2 Intraoperative images. (A) Defect in diaphragm (white arrow) after reducing the contents. (B) Image of the floppy left sided diaphragm, which was delivered out after reducing the content (black arrow showing site of diaphragmatic rupture). (C) Excised thinned out diaphragm with site of rupture. (D) Healthy margins (arrow) of diaphragm after excision of thin part. 

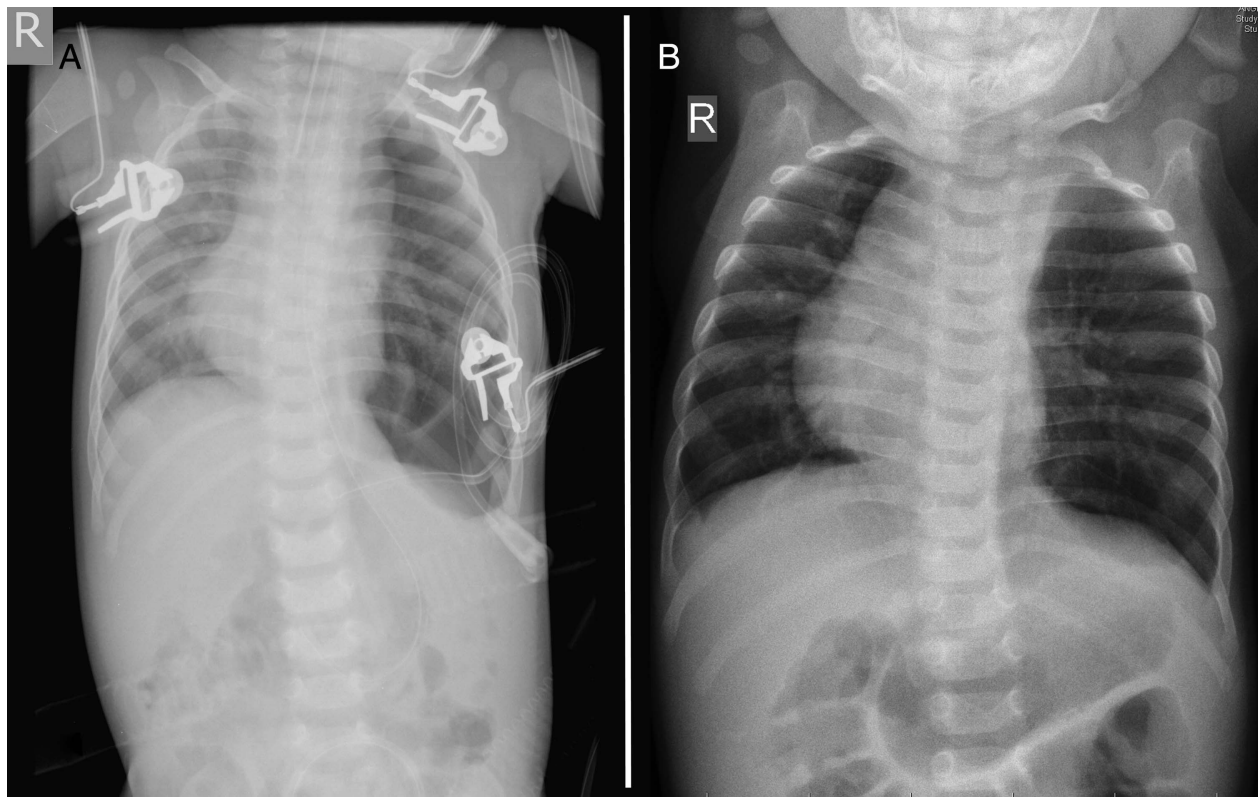

Figure 3 (A) Postoperative chest X-ray. (B) Chest X-ray at discharge.

dyspnoea. A history of antecedent trauma to the chest and abdomen should raise the suspicion of traumatic rupture of diaphragm. Previous chest X-ray, if available, may demonstrate preexisting diaphragmatic eventration. ${ }^{1}$

X-ray of the chest remains the mainstay for diagnosis of diaphragmatic rupture. Findings that suggest diaphragmatic rupture are elevated, interrupted or indistinct hemidiaphragm; air fluid levels or bowel loops in the chest and/or presence of a nasogastric tube in the chest. In doubtful cases, oral contrast studies/CT scan can be utilised for the diagnosis. However, the importance of a high index of clinical suspicion cannot be overemphasised.

Surgery is the treatment for diaphragmatic rupture. Surgical management consists of diaphragmatic repair via laparotomy or thoracotomy. Thoracotomy is preferred for right-sided ruptures due to presence of liver, whereas laparotomy is more useful for left-sided ruptures. Laparoscopic and thoracoscopic approaches have also been described for the treatment of traumatic diaphragmatic ruptures and diaphragmatic eventrations. ${ }^{7} \quad 8$ Uncomplicated diaphragmatic eventrations are treated by plication of the diaphragm. ${ }^{9}$ Repair of the diaphragmatic rupture involves primary closure using interrupted, non-absorbable sutures. Excision of the redundant part of the diaphragm is carried out in cases where the diaphragm is too thin to safely hold the sutures, as in our case. The branches of the phrenic nerve need to be preserved during repair. In our case, we excised only the central thin portion of the left diaphragm, thus minimising the chance of injury to the phrenic nerve. Placement of a mesh is indicated in the repair of large diaphragmatic defects. Use of a mesh reduces the stress associated with continued use of the diaphragm that occurs during breathing, coughing and valsava. ${ }^{10}$

Frequent respiratory infections, wheezing, exercise intolerance and gastric volvulus are well-known complications associated with large diaphragmatic eventration. ${ }^{11}{ }^{12}$ Although rare, a child with diaphragmatic eventration can present with severe breathlessness following spontaneous rupture. Emergency respiratory management followed by appropriate surgical intervention is of utmost importance in saving life and preventing complications.

\section{Learning points}

A spontaneous rupture of congenital eventration of diaphragm is extremely rare.

- A sudden onset of respiratory distress in a child with associated diaphragmatic eventration should raise the suspicion of diaphragmatic rupture even in absence of a preceding trauma or respiratory illness.

- In such cases, emergency respiratory management followed by appropriate surgical intervention is of utmost importance in saving life and preventing complications.

Acknowledgements The authors thank Jujju Jacob Kurian for helping in formatting and rectifying the manuscript.

Competing interests None declared.

Patient consent Obtained.

Provenance and peer review Not commissioned; externally peer reviewed.

\section{REFERENCES}

1 Gun F, Gunendi T, Erginel B, et al. Rupture of a congenital diaphragmatic eventration in a child: report of a case. Surg Today 2011;41:1630-2.

2 Lone RA, Sharma ML, Wani M, et al. Traumatic diaphragmatic rupture, a diagnostic dilemma in the presence of eventration: a case report. Cases J 2009;2:6615.

3 Dutta T. Spontaneous rupture of diaphragm due to pertussis. J Pediatr Surg 1975; 10:147-8.

4 Heuckmann LKP, Schleef J, Uekotter J. Diaphragmatic rupture in pertussis. Monatsschr Kinderheilkd 1996;144:259-62.

5 Akbar A, Parikh DH, Alton H, et al. Spontaneous rupture of the diaphragm. Arch Dis Child 1999;81:341-2.

6 Srpčič MBM. Subacute presentation of spontaneous diaphragmal rupture: a case report. Eur Surg 2005;20:340-2.

7 Martin I, O'Rourke N, Gotley D, et al. Laparoscopy in the management of diaphragmatic rupture due to blunt trauma. ANZ I Surg 1998;68:584-6.

8 Parelkar S, Oak S, Patel J, et al. Traumatic diaphragmatic hernia: management by video assisted thoracoscopic repair. J Indian Assoc Pediatr Surg 2012; 17:180-3. 
$9 \mathrm{Hu}$ J, Wu Y, Wang J, et al. Thoracoscopic and laparoscopic plication of the hemidiaphragm is effective in the management of diaphragmatic eventration. Pediatr Surg Int 2013;30:19-24.

10 Al-Nouri O, Hartman B, Freedman R, et al. Diaphragmatic rupture: Is management with biological mesh feasible? Int J Surg Case Rep 2013;3:349-53.
11 Paris $\mathrm{F}$, Blasco E, Canto A, et al. Diaphragmatic eventration in infants. Thorax 1973;28:66-72.

12 Oh A, Gulati G, Sherman ML, et al. Bilateral eventration of the diaphragm with perforated gastric volvulus in an adolescent. J Pediatr Surg 2000; $35: 1824-6$

Copyright 2015 BMJ Publishing Group. All rights reserved. For permission to reuse any of this content visit

http://group.bmj.com/group/rights-licensing/permissions.

BMJ Case Report Fellows may re-use this article for personal use and teaching without any further permission.

Become a Fellow of BMJ Case Reports today and you can:

- Submit as many cases as you like

- Enjoy fast sympathetic peer review and rapid publication of accepted articles

- Access all the published articles

- Re-use any of the published material for personal use and teaching without further permission

For information on Institutional Fellowships contact consortiasales@bmjgroup.com

Visit casereports.bmj.com for more articles like this and to become a Fellow 